\title{
Reform Practice and Statistical Analysis of College Computer Fundamentals Teaching Based on SPOC Hybrid Mode
}

\author{
Guanghui Feng ${ }^{1}$ \\ ${ }^{1}$ School of Computer Science, Zhuhai College of Jilin \\ University \\ Zhuhai, Guangdong, 519041
}

\author{
Chaoqun Zhang ${ }^{2}$ \\ ${ }^{2}$ ZTE Corporation \\ Shenzhen, Guangdong, 518000
}

\author{
Xiaoyang $\mathrm{Fu}^{1}$, Yu Cheng ${ }^{1}$ \\ ${ }^{1}$ School of Computer Science, Zhuhai College of Jilin University \\ Zhuhai, Guangdong, 519041
}

\begin{abstract}
Based on the analysis of the current situation of Fundamentals of College Computer Application and the actual situation of teaching reform for non-computer majors in Zhuhai College of Jilin University based on SPOC hybrid mode, this paper introduces the design and implementation process of the teaching reform scheme, and tests the effect of teaching reform through the actual teaching application as well as the examination results over the years. The statistical results show that the use of SPOC hybrid teaching mode can reduce class hours, increase the depth and breadth of the course, achieve reasonable allocation of teaching resources, as well as improve students' self-study enthusiasm, operational ability and knowledge proficiency, which is conducive to achieving $\mathbf{N}$ optimal teaching effect.
\end{abstract} NTP

Keywords-SPOC; Computer Fundamentals; Micro-Lecture;

\section{INTRODUCTION}

With the development of network communication, cloud computing, big data, artificial intelligence and other technologies, computer technology has profoundly affected and changed the way of thinking, production, life and learning. The network teaching technology is more mature and the network teaching environment is greatly improved, which makes the college computer fundamental teaching work face many new development opportunities and challenges.

\section{A. The computer level of freshmen is uneven}

On the one hand, the Ministry of Education has formulated the National Ten-Year Development Plan for Educational Informatization (2010-2020) and the Thirteenth Five-Year Plan for Educational Informatization. At present, that Internet access rate of independent school in Guangdong province has reached $100 \%$, and the popularization rate of multimedia classroom has reached $82 \%$; High-quality digital education resources are increasingly abundant, and information-based teaching is becoming more and more popular. Nearly 10 million teachers and students in Guangdong province have explored the teaching, learning and teaching research mode [1] under the network condition through the "network learning space", so the basic level of computer fundamental knowledge of freshmen in colleges and universities is constantly improving. On the other hand, some educational administrations and primary and secondary schools still do not fully recognize the revolutionary influence of information technology on education, which leads to the great difference in students' mastery of basic computer knowledge and brings difficulties to the teaching organization and implementation of the curriculum.

\section{B. The course faces the challenge of limited class hours}

Ordinary colleges and universities mainly aim to train application-oriented talents based on needs of local and regional social and economic development. With the updating and adjustment of discipline and professional training programs, the teaching hours of professional courses are increasing, and the teaching hours of computer fundamental course is decreasing.

\section{The upgrading of the teaching contents of the computer fundamental course}

Enterprises and institutions have higher and higher requirements for the computer level of college graduates, and the actual demand for jobs is often higher than the school teaching content. Guided by the idea of "facing the society, aiming at the position, strengthening the ability and promoting the development" with respect to the public computer course in colleges and universities of Guangdong, the teaching reform of computer fundamental course should carry out the policy that education must serve the social development and economic construction, and meet the practical skill needs of employers [2]. Therefore, the teaching content and the inspection scope of the course should be adjusted, perfected and optimized constantly. 


\section{The reform of teaching method of computer fundamental course}

College computer fundamental course belongs to "using tools" type engineering education course [5], its teaching method should not only refer to the routine teaching method, demonstration method, practice method, experimental method, but along with the rapid development of information technology, combine with modern educational technology to carry out the reform of new compound teaching method.

\section{REFORM PROGRAM AND IMPLEMENTATION PROCESS}

At present, there are 22 computer laboratories in the School of Computer Science of our College, providing more than 1,700 sets of medium and high-grade microcomputers; There are more than 40,000 computer books and more than 30 computer periodicals in the library; The library also provides readers with online information services and abundant electronic resources, so readers can retrieve more than 20 Chinese and foreign network databases. Such hardware infrastructure provides a strong guarantee for teaching reform.

Since 2009, in order to adapt to the development of information sociology and the teaching requirements of reasonable use of network resources, we have largely adjusted the teaching contents, teaching method and teaching hours allocation of computer fundamental course, carried out the teaching reform work, combined the network teaching with classroom teaching, combined the online learning with offline learning, used network teaching platform (NTP), knowledge point "micro-lectures", knowledge point online evaluation system and other new technologies to combine with the traditional classroom teaching and practice teaching in an organic manner. In fact, this teaching mode was SPOC (Small Private Online Course) hybrid mode which was later proposed by Professor Armando Fox -the University of California, Berkeley [3]. SPOC is a small-scale restricted course which is open to the students or specific personnel of the school. Compared with the characteristics of large-scale, open and online learning of MOOC [4], SPOC has the characteristics of small-scale, private, both online and offline mixed learning, which not only overcomes the shortcomings of traditional teaching methods such as discrete and one-sided, but also makes up for the defects of large-scale open MOOC which is difficult to manage and unfavorable to interaction [5-6].

The network learning resources are organized according to the knowledge tree structure divided by chapter, section and point. There are 179 knowledge points, 155 of which can be tested online. Each knowledge point test includes theoretical knowledge test and practical ability test. There are more than a thousand questions that can be tested. For all knowledge points test, it is able to automatically check the assignments and give feedback in time. Students can repeat their test until they reach the required score and pass the knowledge point test. In the network learning platform, 144 knowledge points are equipped with knowledge points explanation "micro-lectures", and the number of videos has reached 528. The course adopts an open learning approach, students can complete the training task of knowledge points in the experimental class or after class, students can consult teachers in the experimental class when they encounter difficulties, discuss with their classmates, search for relevant knowledge on the Internet, and also watch the knowledge points explanation "micro-lectures".

After the teaching reform, the theoretical teaching hours of the course have been reduced from the original 28 hours to 14 hours, and the experimental teaching hours still maintain 28 hours. Theoretical teaching link is based on the teacher-guided learning model, by combining case teaching with flipping classroom. In the limited time, it focuses on the key and difficult problems in the training of students' knowledge points. For example, in the EXCEL teaching, through the analysis and discussion of typical cases and difficult cases, we help students grasp the key and difficult points of learning by combining detailed knowledge and master the operation skills of electronic forms. As shown in Table 1, some EXCEL knowledge points are included in key teaching contents after the teaching reform, but before the teaching reform, these contents are only lightly mentioned, which shows that the depth and breadth of the course have increased after the teaching reform.

TABLE I SOME KEY CONTENTS OF EXCEL AFTER TEACHING REFORM

\begin{tabular}{|c|c|}
\hline \multirow[t]{9}{*}{ Common functions } & Mathematical function ABS, INT, ROUND, TRUNC, RAND \\
\hline & Statistical function: SUM, SUMIF, AVERAGE, COUNT, COUNTIF, COUNTA, MAX, MIN, RANK \\
\hline & Date function: DATE, DAY, MONTH, YEAR, NOW, TODAY, TIME \\
\hline & Conditional function: IF, AND, OR \\
\hline & Financial function: PMT, PV, FV \\
\hline & Frequency distribution function: FREQUENCY \\
\hline & Database statistics function: DCOUNT, DCOUNTA, DMAX, DMIN, DSUM, DAVERAGE \\
\hline & Select function: CHOOSE \\
\hline & Find function: VLOOKUP \\
\hline \multirow{4}{*}{$\begin{array}{l}\text { Concept and operation } \\
\text { of database }\end{array}$} & Sort, data validity \\
\hline & Automatic filter, advanced filter \\
\hline & PivotTable, PivotChart \\
\hline & Subtotal, statistics, \\
\hline
\end{tabular}


The fundamental of computer application is an applied technology course. In the past, we mainly tested the students' learning effect of theoretical knowledge through paper test, which cannot fully reflect the students' practical operation ability. The course assessment mechanism is as shown in Table 2, and in the process assessment stage, it mainly examines students' self-learning ability and practical ability based on information technology. Students of non-music and art majors need to complete the basic knowledge test of computer application on the network learning platform, as well as also complete the Cisco Networking Academy's online course on new Internet technologies. The course requires students to understand the internal components of the computer, understand the configuration of the network and the sharing of resources, and master the ability to set up browser security setting, operating system service packages and security patches downloading and installation, wireless security configuration, and Windows local security strategy configuration etc. In the final examination stage, Guangdong Higher Education Examination Management Center is introduced as the third-party examination and certification organization, and the CCT (Common Computer Test) question bank and the CCT examination form are adopted to carry out the final examination of the course. Qualified students can apply for the CCT first-class certificate voluntarily.

TABLE II ASSESSMENT MECHANISM

\begin{tabular}{|c|c|c|c|}
\hline $\begin{array}{l}\text { Assessment } \\
\text { method }\end{array}$ & Specialty & Proportion & Implementation mode \\
\hline \multirow{3}{*}{$\begin{array}{l}\text { Process } \\
\text { assessment }(40 \%)\end{array}$} & \multirow{2}{*}{$\begin{array}{l}\text { Non-musical and } \\
\text { art major }\end{array}$} & $\begin{array}{l}\text { Test completion proportion of the knowledge points } \\
\text { related to computer application fundamental on the } \\
\text { network learning platform is } 20 \% \text {. }\end{array}$ & $\begin{array}{l}\text { Guangdong Higher Education Examination } \\
\text { Management Center organizes the knowledge point test. }\end{array}$ \\
\hline & & $\begin{array}{l}\text { The assignment completion proportion at Cisco } \\
\text { Networking Academy is } 20 \% \text {. }\end{array}$ & $\begin{array}{l}\text { Cisco Network Academy offers online course on new } \\
\text { Internet technologies }\end{array}$ \\
\hline & $\begin{array}{l}\text { Music and art } \\
\text { major }\end{array}$ & $\begin{array}{l}\text { Test completion proportion of the knowledge points } \\
\text { related to computer application fundamental on the } \\
\text { network learning platform is } 20 \% \text {. }\end{array}$ & $\begin{array}{l}\text { Guangdong Higher Education Examination } \\
\text { Management Center organizes the knowledge point test. }\end{array}$ \\
\hline $\begin{array}{l}\text { Final assessment } \\
(60 \%)\end{array}$ & $\begin{array}{l}\text { All majors of the } \\
\text { whole school }\end{array}$ & Final test $60 \%$ & $\begin{array}{l}\text { Those who pass the application ability test provided by } \\
\text { Guangdong Higher Education Examination } \\
\text { Administration Center may apply for CCT certificate }\end{array}$ \\
\hline
\end{tabular}

\section{STATISTICAL ANALYSIS}

In 2009, our college first carried out pilot reforms in four schools: Electronic Information Science and Technology, Business Administration, International Trade and Finance, and Computer Science and Technology. In 2010, our college began to carry out a comprehensive teaching reform with respect to computer fundamental course for non-computer majors, while School of Computer Science dropped out of the course. In the third-party certification examination provided by Guangdong Higher Education Examination Management Center, the first-time pass rate reached $74.56 \%$ in 2010 , nearly $10 \%$ higher than that in 2009; The first-time pass rate has been above $80 \%$ between 2011 and 2016; The excellence rate has increased year by year, reaching $11.02 \%$ in 2016 when the rate exceeds $10 \%$ for the first time.
Since 2017, our college has been further deepening the teaching reform, and has upgraded Windows operation and Office modules represented by Word, Excel and PPT from Windows XP to Windows 2010 and Office 2003 to Office 2010, respectively, and has launched an online self-learning course on new Internet technologies provided by Cisco for non-music and art majors. As a result of the updating of learning content and the increase in learning tasks, the first-time pass rate in 2017 dropped to $79.28 \%$ and the excellence rate dropped to $1.33 \%$. By 2018, teachers and students gradually adapt to the changes of the curriculum, the first-time pass rate increased rapidly to $86.63 \%$, the excellent rate increased to $14.43 \%$. The status of the third-party certification examination from 2009 to 2018 is shown in Table 3 .

TABLE III STATUS OF THIRD-PARTY CERTIFICATION EXAMINATION 2009-2018

\begin{tabular}{lllllll}
\hline Year & $\begin{array}{l}\text { Actual number } \\
\text { examinees }\end{array}$ & $\begin{array}{l}\text { The number of passing the } \\
\text { examination }\end{array}$ & $\begin{array}{l}\text { Average } \\
\text { score }\end{array}$ & $\begin{array}{l}\text { Failure } \\
\text { rate }\end{array}$ & Pass rate & $\begin{array}{l}\text { Excellence } \\
\text { rate }\end{array}$ \\
\hline 2009 & 2493 & 1619 & 63.64 & $35.06 \%$ & $64.94 \%$ & $0.92 \%$ \\
\hline 2010 & 6588 & 4912 & 66.49 & $25.44 \%$ & $74.56 \%$ & $1.67 \%$ \\
\hline 2011 & 6967 & 5668 & 69.33 & $18.65 \%$ & $81.35 \%$ & $1.84 \%$ \\
\hline 2012 & 6664 & 5623 & 71.68 & $15.62 \%$ & $84.38 \%$ & $4.79 \%$ \\
\hline 2013 & 6220 & 5337 & 72.10 & $14.20 \%$ & $85.80 \%$ & $5.47 \%$ \\
\hline 2014 & 6589 & 5729 & 73.52 & $13.05 \%$ & $86.95 \%$ & $5.13 \%$ \\
\hline 2015 & 6915 & 5739 & 71.37 & $17.01 \%$ & $82.99 \%$ & $5.28 \%$ \\
\hline 2016 & 6499 & 5585 & 73.37 & $14.06 \%$ & $85.94 \%$ & $11.02 \%$ \\
\hline 2017 & 6303 & 4997 & 67.47 & $20.72 \%$ & $79.28 \%$ & $1.33 \%$ \\
\hline 2018 & 6763 & 5859 & 75.38 & $13.37 \%$ & $86.63 \%$ & $14.43 \%$ \\
\hline
\end{tabular}


The statistical results of the micro-lectures playback rate of knowledge point and the completion rate of the knowledge

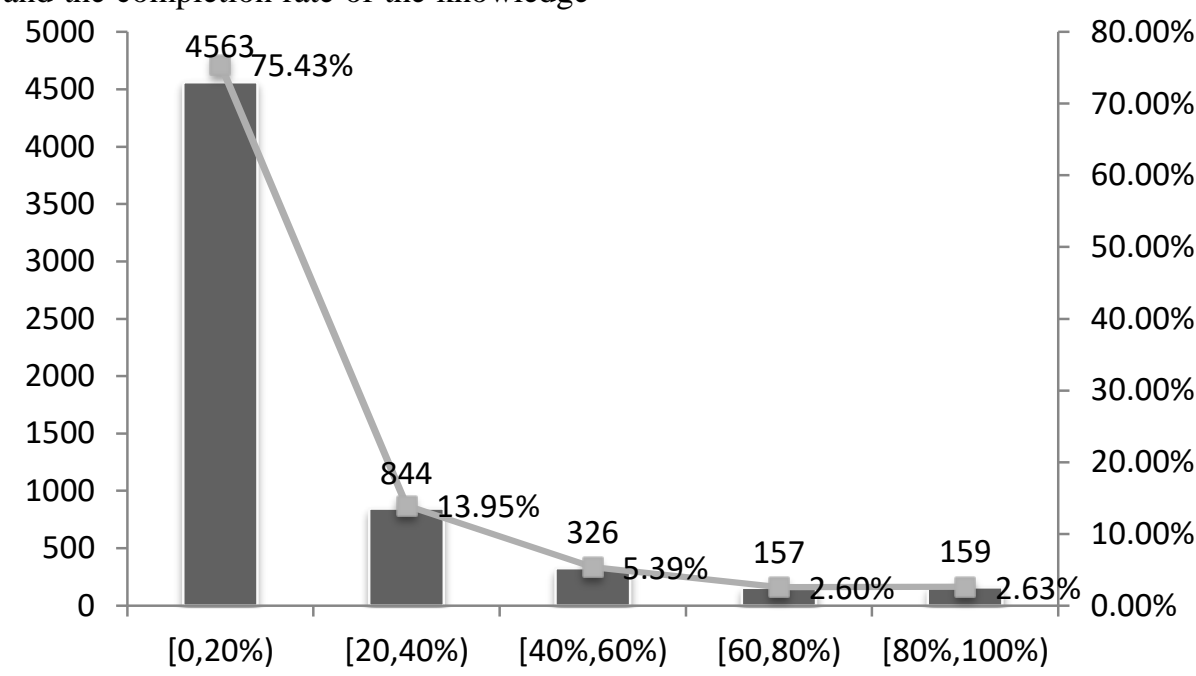

Number of students - Proportion of the total students

Fig. 1 Micro-lectures playback rate of knowledge points

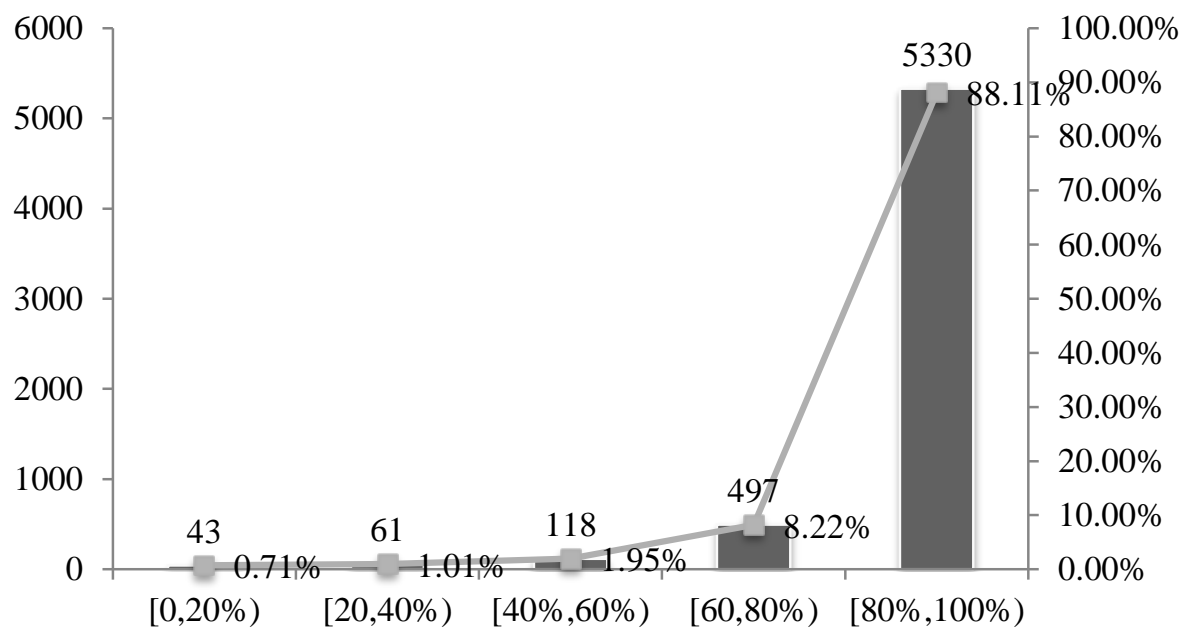

Number of students $\quad-$ Proportion of the total students

Fig. 2 Knowledge point test completion rate

It is not difficult to find that the review status of knowledge point micro-lectures is just the opposite of the completion status of knowledge point test. $75.34 \%$ of the students watched knowledge point micro-lectures in the proportion of less than $20 \%$ of the total number of micro-lectures, on the contrary, $88.11 \%$ of the students completed knowledge point test in the proportion of more than $80 \%$ of the total number of knowledge points test; only $2.63 \%$ of the students watched knowledge point micro-lectures in the proportion of more than $80 \%$ of the total number of micro-lectures, and $0.71 \%$ of the students completed knowledge point test in the proportion of less than $20 \%$ of the total number of knowledge points test.

The learning condition of Cisco Internet New Technology course for 5,895 non-music and art graduates in Grade 2018 is shown in Figure 3. Among which, 5,769 students, or $97.86 \%$ of the total students, have independently completed their courses. $95.86 \%$ of the students got 80 scores or above in the test through independent learning. 


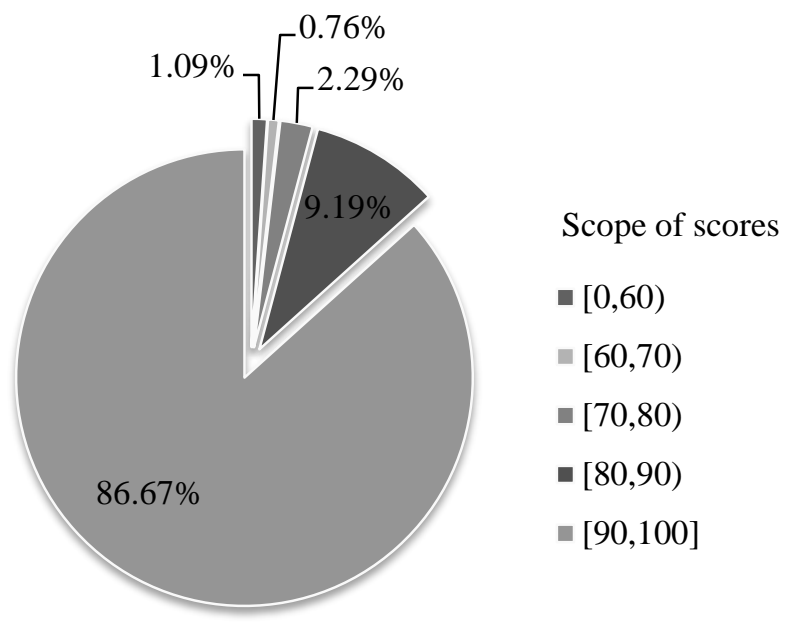

Fig. 3 Cisco Internet New Technology Course for Non-Music and Arts Majors, Grade 2018

\section{CONCLUSION}

The teaching reform of college computer fundamental based on SPOC hybrid mode embodies the following characteristics: The combination of high standard and high efficiency, combination of network teaching and classroom teaching, combination of teachers' teaching and students' self-study, combination of teaching ideas and methods and the cultivation of continuous learning ability, and the combination of final examination and computer proficiency test. The reform of course learning mode offers students a space to develop their talents and change from the passive indoctrination learning into active exploration learning, enables students to have the ability of independent learning and lifelong learning, and makes them more adaptive to the needs of today's social and economic development.

\section{ACKNOWLEDGMENT}

This work was financially supported by:

(1) Premier-Discipline Enhancement Scheme Supported by Zhuhai Government (Grant No. 2015YXXK02-2);

(2) Premier Key-Discipline Enhancement Scheme Supported by Guangdong Government Funds (Grant No. 2016GDYSZDXK036);

(3) Zhuhai Laboratory of Key Laboratory of Symbolic Computation and Knowledge Engineering of Ministry of Education, the Natural Science Foundation of Guangdong Province (Grant No. 2016A030313658).

\section{REFERENCES}

11] Guangdong Provincial Department of Education. The 13th Five-Year Plan for Educational Informationization Development in Guangdong Province [EB/OL]. http://zwgk.gd.gov.cn. May 24, 2017

[2] Huiwen YE, Xuanjie DU, Liping LI. An Investigation and Analysis Report on the Effect of the Course Reform of University Computer Application Fundamental in South China Normal University [J]. Computer Education, 2009 (12): 154-158

[3] Fu WANG and Yun CUI. From MOOC to SPOC: Research on Hybrid Teaching Mode in Universities Based on Gadamer's Theory of Horizon Fusion [J]. Journal of Mianyang Normal University, 2019 (3): 34-38.

[4] Harvard University. Insight [EB/OL] https://harvardx.harvard.edu/insights. 2018-03-12.

[5] Guanghui FENG, Yanchun LIANG, Wei LV, etc. Reform and Research of SPOC Blended Teaching Models Against the Backdrop of Internet $+[\mathrm{J}]$. Advances in Social Science, Education and Humanities Research (ICCESD 2019), 2019,332:191-194.

[6] Yaohui CHANG Teaching Reform and Practice of Programming Course Based on SPOC Hybrid Teaching Mode--A Case Study on Visual Basic Programming Fundamental [J]. Industry and Information Education, 2017 (01): 26-32

[7] Lixin ZHAO. Research on the Application of SPOC in Computer Application Fundamental in Higher Vocational Colleges [J]. Journal of Shijiazhuang Vocational and Technical College, 2018, 30 (06): 78-83.

[8] Shunli CHEN. Research and Practice on Three-dimensional Construction of Basic Textbooks for Computer Application in Higher Vocational Education under Internet + Education Mode [J]. Journal of Ningbo Radio and TV University, 2017, 15 (3): 91-94. 